\title{
GESCHICHTE \\ DER \\ ANTIKEN PHILOSOPHIE
}

VON

E. V. ASTER

PROFESSOR AN DER UNIVERSITAT MUNCHEN

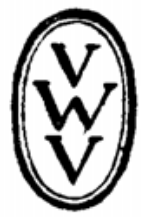

BERLIN UND LEIPZIG 1920

VEREINIGUNG WISSENSCHAFTLICHER VERLEGER WALTER DE GRUYTER @ CO.

VORMALS G.J.GOSCHEN'SCHE VERLAGSHANDLUNG :: J.GUTTENTAG, VERLAGSBUCHBANDLUNG :: GEORG REIMER :: KARL J. TRUBNER :: VEIT \& COMP. 
Alle Rechte, einschließlich dos Übersetzungsrochts, vorbehalten. 